\title{
25ook Reviems.
}

A Thousand Books for the Hospital Library. Selected from the shelf-list of the Library of McLean Hospital, Waverley, Massachusetts, by EDrTH KATHLEeN JoNes, Librarian. With additions and annotations by MIRIAM E. Carey, Supervisor of Institution Libraries, Minnesota State Board of Control; Florence WaUGH, Librarian for State Institutions, Nebraska Library Commission, and Julia A. Robinson, Secretary, Iowa Library Commission. (Chicago: American Library Association Publishing Board, 1913.)

Anyone who has ever tried to select books for hospital use can appreciate how valuable this list may prove. The McLean Hospital has one of the oldest patients' libraries in this country, where Miss Jones has had considerable service and has been able to profit by the experience of her predecessors who have weeded out undesirable books and by their records have shown the most popular and most desirable. Miss Jones's work has also been criticized and augmented by her collaborators. An excellent foreword indicates the principles which have guided the selection of this list and will be helpful to anyone having charge of a library. We believe that no hospital should be without this list, as it is a most valuable guide for the selection of books for patients' use. Every institution should have a library even though it has no trained librarian, and this list will prevent the purchase or accumulation of unsuitable books. The comments on the books are especially valuable to the untrained librarian or person in charge of the books which form the nucleus of a library.

W. R. D.

The Modern Treatment of Nervous and Mental Diseases. By American and British Authors. Edited by William A. White, M. D., Superintendent of the Government Hospital for the Insane, Washington, D. C., etc., and Smith Ely Jelliffe, A. M., M. D., Ph. D., etc. In two volumes. (Philadelphia and New York: Lea E Febiger, 1913.)

We are told in the preface that "these volumes, devoted to the treatment of nervous and mental diseases, are designed to meet the needs which the rapid advances in the knowledge of neurology and psychiatry have created. The nervous system is here regarded as a whole and as inclusive of the mind, and it is maintained that disturbances of any and all of its functions, mental as well as physical, are proper subjects for therapeutics . ..." The present work lays emphasis upon the psychical side of life as being worth quite as much consideration as the physical. It sets forth doctrines of nervous and mental hygiene, reconstructive factors in social organization 